ECCOMAS

Proceedia
EUROGEN 2021

$14^{\text {th }}$ ECCOMAS Thematic Conference on Evolutionary and Deterministic Methods for Design, Optimization and Control N. Gauger, K. Giannakoglou, M. Papadrakakis, J. Periaux (eds.) Streamed from Athens, Greece, 28-30 June 2021

\title{
OPTIMUM DESIGN OF REINFORCED CONCRETE RETAINING WALLS BY USING SPECIFIC PARAMETER-FREE METAHEURISTIC ALGORITHMS
}

\author{
Melda Yücel ${ }^{1}$, Gebrail Bekdaş ${ }^{1}$, Sinan Melih Nigdeli1 and Aylin Ece Kayabekir ${ }^{1}$ \\ ${ }^{1}$ Department of Civil Engineering, Istanbul University - Cerrahpaşa \\ Avcılar, Istanbul, Turkey \\ e-mail: melda.yucel@yahoo.com.tr, bekdas@istanbul.edu.tr, melihnig@istanbul.edu.tr, ecekay- \\ abekir@gmail.com
}

\begin{abstract}
In the optimum design of structural systems, the robustness and the performance are related to the best tuning of the parameters of the method. For metaheuristic algorithms inspired by phenomena in life, algorithm-specific parameters exist in addition to general parameters that are the population of the generated candidate solution and the number of iterations that are needed to find the final optimum solution. In the optimum design of reinforced concrete $(R C)$ structures, the dimensions are optimized by considering the minimization of the total cost. These problems are highly constrained by the design requirements presented in design codes. Especially, $R C$ retaining walls involve the check of stability conditions as geotechnical state limits in addition to structural state limits. This situation makes the optimization problem challenging. A better and robust algorithm is always in search. In the present study, two specific parameter-free metaheuristic algorithms are employed. These algorithms are teaching-learning-based optimization (TLBO) and Jaya algorithm (JA). Since JA is a single-phase algorithm and both phases of TLBO defined as teacher and learner phases are consequently applied, a switch probability is not needed. Also, the existing factor is defined randomly. These two algorithms were tested on three cases and the results were compared with three classical algorithms such as Genetic Algorithm (GA), Differential Evaluation (DE), and Particle Swarm Optimization (PSO). In this verification, JA needs less function evaluation to reach the optimum results. As conclusions, both TLBO and JA are robust methods for the optimization problem.
\end{abstract}

Keywords: Reinforced Concrete, Retaining Walls, Optimization, Metaheuristic Algorithms 


\section{INTRODUCTION}

Generally, engineering designs are carried out by taking two main objectives into consideration. The first of these is structural security, the other is cost. Good engineering design can be defined as the best combination or balance of these two objectives. The process in which this balance is investigated is called optimization and the obtained result is called optimum design.

Different methods have been developed and used from past to present in order to find the optimum design in engineering designs. Especially in recent years, metaheuristic algorithms are one of the methods used frequently for this purpose. Metaheuristic algorithms are methods developed by taking inspiration from nature. Examples of these are genetic (GA) [1,2] and differential evolution (DE) [3] algorithms from the evolutionary process, flower pollination (FPA) [4] from the pollination process of flowers, the bat algorithm (BA) [5] from the echolocation characteristics of bats, the gray wolf optimization (GWO) [6] from the herd hierarchy and hunting processes of the gray wolves, the particle swarm optimization (PSO) [7] from the herd movement of living things, ant colony optimization (ACO) [8] from the foraging process of ants, teaching-learning-based optimization (TLBO) [9] from the student-teacher relationship and learning in a classroom.

An optimization process is carried out using metaheuristic algorithms in many areas of structural engineering. One of these areas is the optimum design of reinforced concrete structures. Since reinforced concrete structures consist of two different mechanical and cost-effective materials, it is necessary to find a combination that will provide the lowest cost (optimum design) of concrete and steel. The optimum design of RC retaining walls is one of the areas that have been researched extensively. Various metaheuristic methods such as Simulated Annealing (SA) [10,11], PSO [12], Harmony search (HS) [13] Big Bang Big Crunch (BB-BC) [14], Firefly Algorithm (FA) [15], FPA [16] have been used in the design of RC retaining walls. In addition to these studies, there are also studies where performance evaluation of algorithms [17] is performed and modified or hybrid algorithms [18] are used.

In this study, the effect of different parameters on optimum RC retaining wall design was investigated. For this purpose, five different metaheuristic algorithm-based methods have been developed. In this way, as a result of the study, the researchers were informed about the effects of parameters as well as the most effective metaheuristic method for optimum design.

\section{OPTIMUM DESIGN VIA METAHEURISTIC ALGORITHMS}

Metaheuristic methods can generally be summarized with 3 stages as given in Fig.1.

In the first stage (pre-optimization), the design constants of the problem, the lower and upper limits of the design variables, the population number (pn), the algorithm-specific parameters and the stopping criteria of the optimization are defined. Then, candidate solutions (totally pn) are generated according to Eq. (1) and stored in initial solution matrix.

$$
X_{i}=X_{i, \min }+\operatorname{rand}\left(X_{i, \max }-X_{i, \min }\right)
$$

In Eq. (1), $X_{i}, X_{i, \min }$ and $X_{i, \max }$ represent $i^{\text {th }}$ candidate solution, minimum and maximum limits of $i^{\text {th }}$ solution respectively. rand is a function that is generated by random values between 0 and 1.

The second stage is the analysis stage. In this stage, the objective function of each solution is calculated, and the design constraints of the problem are checked. Objective functions of solutions that violate the design constraint are penalized using a penalization value. Within the scope of this study, the objective function is determined as the minimum material cost given as Eq.(2), and for the penalization, a high value is defined. 


$$
\min (f(x))=C_{c} V_{c}+C_{s} W_{s}
$$

In Eq. (2), $C_{c}$ and $C_{s}$ are unit concrete and unit reinforcing steel costs respectively. $V_{c}$ and $W_{s}$ represent the volume of the concrete and unit volume weight of the steel, respectively.

At the last stage (optimization stage), an iterative process is started. In this process, first of all new solution matrix is generated according to algorithm equations. In this study, 5 different algorithms, GA, DE, PSO, TLBO and JA were employed and algorithm-specific equations are given below.

Equation of genetic algorithm (GA):

$$
X_{q, \text { new }}=\left\{m r>\text { rand }, \quad X_{q, \text { min }}+\operatorname{rand}\left(X_{q, \max }-X_{q, \min }\right)\right.
$$

In Eq. (3), $m r$ is mutation rate, $\mathrm{q}$ is a gene (design parameter) randomly-selected from the total design parameter. $X_{q, n e w}, X_{q, \min }$ and $X_{q, \max }$ are new design variable, lower and upper limit values of $q^{\text {th }}$ design variable, respectively. Unlike GA, DE uses two equations (Eq. 4 and 5 ). New design variables are derived by selecting one of these two equations according to DE rules.

$$
\begin{gathered}
X_{i, \text { new }}=X_{i, p}+F\left(X_{i, q}-X_{i, r}\right) \\
\mathrm{X}_{\mathrm{i}, \mathrm{j}}=\mathrm{X}_{\mathrm{i}, \text { new }} \quad\left\{\text { if rand } \leq \mathrm{CR} \quad \text { or } \quad \mathrm{cs}=\text { rand }_{\mathrm{cs}}\right.
\end{gathered}
$$

In Eq. (4 and 5), $X_{i, p}, X_{i, q}, X_{i, r}$ represent randomly selected different solutions and $F$ is the weighting factor. $C R, c s$, and rand $_{c s}$ are crossover possibilities, current candidate solution, and randomly selected solution.

In PSO, new values are found by using a single equation as in GA. This equation as follows

$$
X_{i, \text { new }}=X_{i, j}+V_{i, \text { new }}
$$

where $X_{i, j}$ is the current position of $\mathrm{j}^{\text {th }}$ particle and $V_{i, n e w}$ can be calculated with Eq. (7).

$$
V_{i, \text { new }}=w V_{i, j}+c_{1} \operatorname{rand}\left(X_{i, y_{\text {best }}}-X_{i, j}\right)+c_{2} \operatorname{rand}\left(X_{i, g_{\text {best }}}-X_{i, j}\right)
$$

In Eq. (7), $V_{i, j}$ is current velocity $j^{\text {th }}$ particle. $X_{i, y_{\text {best }}}$ and $X_{i, g_{\text {best }}}$ represent values of the best global and local positions respectively. $c_{1}$ and $c_{2}$ are positive constant parameters used to control velocity.

In the TLBO algorithm, two different equations are used in generating new solutions. However, unlike other two-equation algorithms, it uses both of the equations one after the other instead of choosing one of the equations. These equations are as follows

$$
\begin{gathered}
\mathrm{X}_{\mathrm{i}, \text { new }}=\mathrm{X}_{\mathrm{i}, \mathrm{j}}+\operatorname{rand}\left(\mathrm{X}_{\mathrm{i}, \text { best }}-(\mathrm{TF}) \mathrm{X}_{\mathrm{i}, \text { mean }}\right) \\
X_{i, \text { new }}= \begin{cases}O F_{a}<O F_{b}, & X_{i, j}+\operatorname{rand}\left(X_{i, a}-X_{i, b}\right) \\
O F_{a}>O F_{b}, & X_{i, j}+\operatorname{rand}\left(X_{i, b}-X_{i, a}\right)\end{cases}
\end{gathered}
$$

where $\mathrm{X}_{\mathrm{i}, \mathrm{j}}, \mathrm{X}_{\mathrm{i}, \text { best }}$, $\mathrm{X}_{\mathrm{i}, \text { mean }}$ represent values of existing solution, best solution and mean values of existing solutions respectively, and TF shows teaching factor. $X_{i, a}$ and $X_{i, b}$ are randomly selected candidate solutions. Objective functions corresponding to these solutions $\left(\mathrm{X}_{\mathrm{i}, \mathrm{a}}\right.$ and $\left.\mathrm{X}_{\mathrm{i}, \mathrm{b}}\right)$ are expressed with $\mathrm{OF}_{\mathrm{a}}$ and $\mathrm{OF}_{\mathrm{b}}$, respectively.

The other algorithm used in the study, JA uses a single equation given in Eq.(10).

$$
X_{i, \text { new }}=X_{i, j}+\operatorname{rand}\left(X_{i, \text { best }}-\left|X_{i, j}\right|\right)-\operatorname{rand}\left(X_{i, \text { worst }}-\left|X_{i, j}\right|\right)
$$


In Eq.(10), $X_{i, \text { worst }}$ is worst solution in terms of the objective function.

After the generation of new solution matrix, it is done comparation between solution matrix and existing one. In case of new solutions have better objective function value, new solutions replace existing solutions. In case new solutions have better objective function value, the existing solution matrix is updated with new solutions. This process is continued until satisfying stopping criteria of the problem. In this study maximum iteration number is determined as stopping criteria.

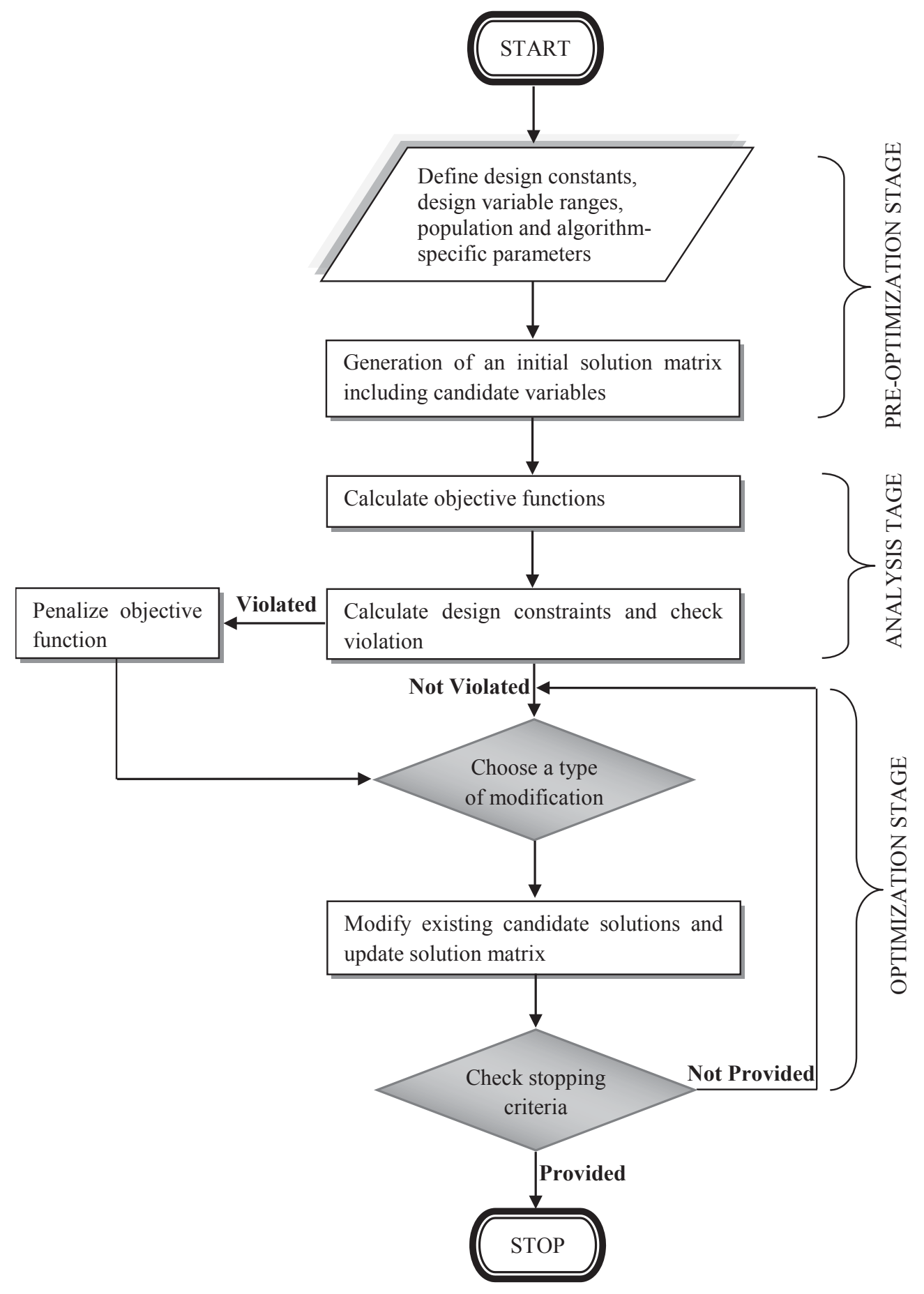

Figure 1: The optimization flowchart 


\section{NUMERICAL EXAMPLE}

$\mathrm{RC}$ retaining wall that is investigated for the optimum design can be seen in Fig.2. As shown in the figure, there are 5 design variables. The limits of these design variables and the design constants are presented in Table 1. In reinforced concrete design, the constraints of ACI 318 [19] regulation were applied. Information on the constraints applied in the optimization process is given in Table 2. In addition to these, various load and safety factors are summarized in Table 3.

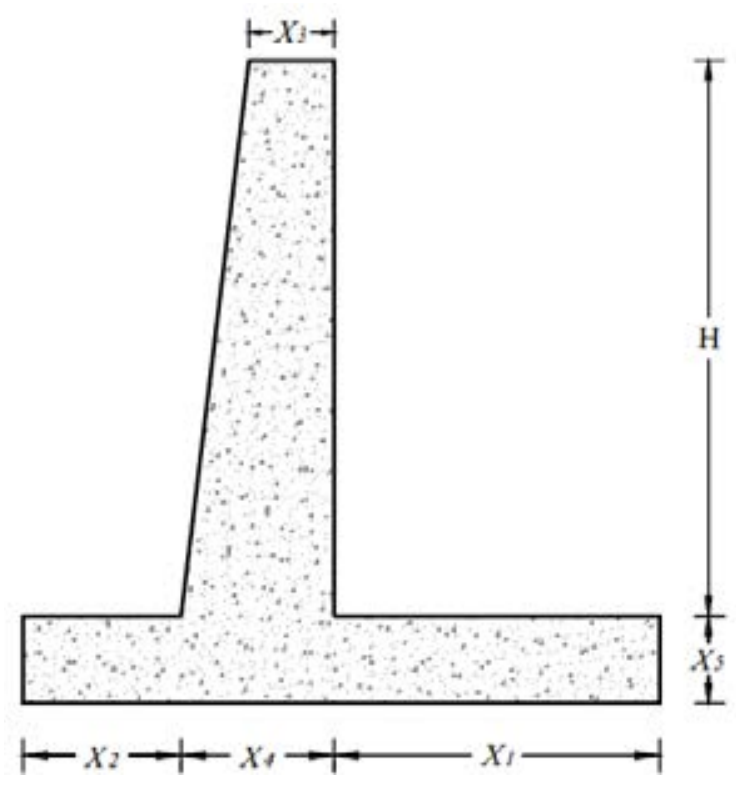

Figure 2: Design variables Cantilever retaining wall

Table 1. Optimization data for $\mathrm{T}$ shape walls respect to a specific design

\begin{tabular}{|c|c|c|c|c|}
\hline & Definition & Symbol & Limit/Value & Unit \\
\hline \multirow{5}{*}{ 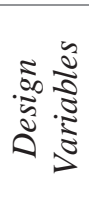 } & Heel slab/back encasement width of retaining wall & $\mathrm{X}_{1}$ & $0-10$ & $\mathrm{~m}$ \\
\hline & Toe slab/front encasement width of retaining wall & $\mathrm{X}_{2}$ & $0-3$ & $\mathrm{~m}$ \\
\hline & Upper part width of cantilever/stem of wall & $\mathrm{X}_{3}$ & $0.2-3$ & $\mathrm{~m}$ \\
\hline & Bottom part width of cantilever/stem of wall & $\mathrm{X}_{4}$ & $0.3-3$ & $\mathrm{~m}$ \\
\hline & Thickness of bottom slab of retaining wall & $\mathrm{X}_{5}$ & $0.3-3$ & $\mathrm{~m}$ \\
\hline \multirow{15}{*}{ 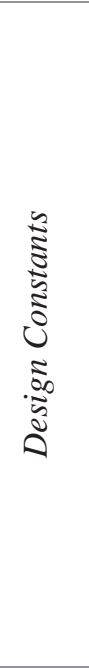 } & $\begin{array}{l}\text { Difference between top elevation of bottom-slab with soil } \\
\text { in behind of wall (active zone)/stem height }\end{array}$ & $\mathrm{H}$ & 6 & $\mathrm{~m}$ \\
\hline & Weight per unit of volume of back soil of wall (active zone) & $\gamma_{\mathrm{z}}$ & 18 & $\mathrm{kN} / \mathrm{m}^{3}$ \\
\hline & Surcharge load in active zone (on top elevation of soil) & $\mathrm{q}_{\mathrm{a}}$ & 10 & $\mathrm{kN} / \mathrm{m}^{2}$ \\
\hline & Angle of internal friction of back soil of wall & $\Phi$ & $30^{\circ}$ & \\
\hline & Allowable bearing value of soil & $\mathrm{q}_{\text {safety }}$ & 300 & $\mathrm{kN} / \mathrm{m}^{2}$ \\
\hline & Thickness of granular backfill & $t_{b}$ & 0.5 & $\mathrm{~m}$ \\
\hline & Coefficient of soil reaction & $\mathrm{K}_{\text {soil }}$ & 200 & $\mathrm{MN}$ \\
\hline & Compressive strength of concrete & $f_{c}$ & 25 & $\mathrm{MPa}$ \\
\hline & Tensile strength of steel reinforcement & $f_{y}$ & 420 & $\mathrm{MPa}$ \\
\hline & Elasticity modulus of concrete & $E_{s}$ & 200000 & MPa \\
\hline & Weight per unit of volume for concrete & $\gamma_{\mathrm{c}}$ & 25 & $\mathrm{kN} / \mathrm{m}^{3}$ \\
\hline & Weight per unit of volume for steel & $\gamma_{\mathrm{s}}$ & 7.85 & $\mathrm{t} / \mathrm{m}^{3}$ \\
\hline & Width of wall bottom slab & $\mathrm{b}$ & 1000 & $\mathrm{~mm}$ \\
\hline & Concrete unit cost & $\mathrm{C}_{\mathrm{c}}$ & 50 & $\$ / \mathrm{m}^{3}$ \\
\hline & Steel unit cost & $\mathrm{C}_{\mathrm{s}}$ & 700 & $\$ /$ ton \\
\hline
\end{tabular}


Table 2. The design constraints

\begin{tabular}{ll}
\hline Description & Constraints \\
\hline Safety for overturning stability & $\mathrm{g}_{1}(\mathrm{X}): \mathrm{FoS}_{\mathrm{ot}, \mathrm{design}} \geq \mathrm{FoS}_{\mathrm{ot}}$ \\
Safety for sliding & $\mathrm{g}_{2}(\mathrm{X}): \mathrm{FoS}_{\mathrm{s}, \mathrm{design}} \geq \mathrm{FoS}_{\mathrm{s}}$ \\
Safety for bearing capacity & $\mathrm{g}_{3}(\mathrm{X}): \mathrm{FoS}_{\mathrm{bc}, \mathrm{design}} \geq \mathrm{FoS}_{\mathrm{bc}}$ \\
Minimum bearing stress $\left(q_{\min }\right)$ & $\mathrm{g}_{4}(\mathrm{X}): q_{\min } \geq 0$ \\
Flexural strength capacities of critical sections $\left(M_{d}\right)$ & $\mathrm{g}_{5-7}(\mathrm{X}): M_{d} \geq \mathrm{M}_{\mathrm{u}}$ \\
Shear strength capacities of critical sections $\left(V_{d}\right)$ & $\mathrm{g}_{8-10}(\mathrm{X}): V_{d} \geq \mathrm{V}_{\mathrm{u}}$ \\
Minimum reinforcement areas of critical sections $\left(A_{\text {smin }}\right)$ & $\mathrm{g}_{11-13}(\mathrm{X}): \mathrm{A}_{\mathrm{s}} \geq A_{\text {smin }}$ \\
Maximum reinforcement areas of critical sections $\left(A_{\text {smax }}\right)$ & $\mathrm{g}_{14-16}(\mathrm{X}): \mathrm{A}_{\mathrm{s}} \leq A_{\text {smax }}$ \\
\hline
\end{tabular}

Table 3. ACI 318 Regulation values utilized in optimization process

\begin{tabular}{lcc}
\hline Load Coefficients in ACI Regulation & Symbol & Value \\
\hline Coefficient for load increment & $\mathrm{C}_{\mathrm{l}}$ & 1.7 \\
Reduction coefficient for section bending moment capacity & $\mathrm{FiM}$ & 0.9 \\
Reduction coefficient for section axial load capacity & $\mathrm{FiN}$ & 0.9 \\
Reduction coefficient for section shear load capacity & $\mathrm{FiV}$ & 0.75 \\
Constant load coefficient & $\mathrm{G}_{\mathrm{K}}$ & 0.9 \\
Live load coefficient & $\mathrm{Q}_{\mathrm{K}}$ & 1.6 \\
Horizontal load coefficient & $\mathrm{H}_{\mathrm{K}}$ & 1.6 \\
Safety coefficient respect to overturning & Os $_{\text {afety }}$ & 1.5 \\
Safety coefficient respect to slipping & $\mathrm{Ss}_{\text {afety }}$ & 1.5 \\
\hline
\end{tabular}

Three different case analyses were performed using GA, DE, PSO, TLBO and JA. These cases are as follows:

Case 1: Optimum design variables are investigated using thirty multiple cycles of optimization. In the optimization process, twenty populations and five thousand iteration numbers are used.

Case 2: Effect of wall height on the optimum design as well as algorithm performances are investigated. As different from Case $1, \mathrm{H}$ is defined as $10 \mathrm{~m}$.

Case 3: Best population and iteration number combination are investigated. For this investigation, optimization operations are carried out for different maximum iteration numbers from 1 to 5000 by increasing 499 in each step and for different population numbers such as $3,5,10$, $15,20,25,30$.

The optimum results for these cases are shown in Table 4-6, respectively.

Table 4. Optimum design results for Case 1.

\begin{tabular}{lllllllll}
\hline Algorithm & $\mathbf{X}_{\mathbf{1}}$ & $\mathbf{X}_{\mathbf{2}}$ & $\mathbf{X}_{\mathbf{3}}$ & $\mathbf{X}_{\mathbf{4}}$ & $\mathbf{X}_{\mathbf{5}}$ & Min. Cost & Ave. Cost & Standard Dev. \\
\hline GA & 4.1257 & 0.0003 & 0.2003 & 0.6212 & 0.4274 & 428.2421 & 449.3181 & 36.9566092 \\
DE & 4.1323 & 0.0000 & 0.2000 & 0.6098 & 0.4267 & 428.1139 & 433.3653 & 11.4300331 \\
PSO & 4.1322 & 0.0000 & 0.2000 & 0.6099 & 0.4267 & 428.1139 & 449.2315 & 40.6569904 \\
TLBO & 4.1323 & 0.0000 & 0.2000 & 0.6099 & 0.4267 & 428.1139 & 428.1139 & 0.0000005 \\
JA & 4.1323 & 0.0000 & 0.2000 & 0.6099 & 0.4267 & 428.1139 & 428.1139 & 0.0000012 \\
\hline
\end{tabular}

Table 5. Optimum design results for Case 2.

\begin{tabular}{lllllllll}
\hline Algorithm & $\mathbf{X}_{\mathbf{1}}$ & $\mathbf{X}_{\mathbf{2}}$ & $\mathbf{X}_{\mathbf{3}}$ & $\mathbf{X}_{\mathbf{4}}$ & $\mathbf{X}_{\mathbf{5}}$ & Min. Cost & Ave. Cost & Standard Dev. \\
\hline GA & 6.3735 & 1.5040 & 0.2010 & 1.3299 & 0.7140 & 1365.7614 & 1370.8030 & 5.8839356 \\
DE & 6.3480 & 1.4917 & 0.2000 & 1.3656 & 0.7086 & 1365.2365 & 1442.5197 & 146.3331618 \\
PSO & 6.3482 & 1.4879 & 0.2000 & 1.3655 & 0.7074 & 1365.2432 & 1473.0711 & 137.6288067 \\
TLBO & 6.3479 & 1.4920 & 0.2000 & 1.3658 & 0.7087 & 1365.2365 & 1365.2368 & 0.0001623 \\
JA & 6.3478 & 1.4919 & 0.2000 & 1.3660 & 0.7087 & 1365.2367 & 1371.6683 & 34.6327849 \\
\hline
\end{tabular}


Table 6. Optimum design values of wall with the best population-iteration combinations

\begin{tabular}{lllllllllll}
\hline Algorithm & $\mathbf{X}_{\mathbf{1}}$ & \multirow{2}{*}{$\mathbf{X}_{\mathbf{2}}$} & $\mathbf{X}_{\mathbf{3}}$ & $\mathbf{X}_{\mathbf{4}}$ & $\mathbf{X}_{\mathbf{5}}$ & Min. Cost & Ave. Cost & Standard Dev. & $\begin{array}{l}\text { Iter. } \\
\text { Num. }\end{array}$ & $\begin{array}{l}\text { Pop. } \\
\text { Num. }\end{array}$ \\
\hline GA & 4.1304 & 0.0046 & 0.2001 & 0.6106 & 0.4240 & 428.2186 & 428.6384 & 0.34408003 & 2995 & 15 \\
DE & 4.1323 & 0.0000 & 0.2000 & 0.6098 & 0.4267 & 428.1139 & 428.1139 & 0.0000000 & 1997 & 30 \\
PSO & 4.1324 & 0.0000 & 0.2000 & 0.6096 & 0.4267 & 428.1140 & 699.2741 & 732.5740371 & 3993 & 30 \\
TLBO & 4.1323 & 0.0000 & 0.2000 & 0.6098 & 0.4267 & 428.1139 & 428.1139 & 0.0000126 & 4991 & 25 \\
JA & 4.1323 & 0.0000 & 0.2000 & 0.6099 & 0.4267 & 428.1139 & 428.1139 & 0.0000057 & 4492 & 25 \\
\hline
\end{tabular}

\section{CONCLUSION}

\subsection{Case 1}

DE, PSO, TLBO and JA find close values in terms of objective functions (minimum cost), whereas GA could not reach the minimum value. Therefore, it can be said that all algorithms except GA are effective in finding the minimum result. However, as seen in Table 4, the standard deviation and average cost values of the DE and PSO algorithms are higher than other ones. Therefore, it can be concluded that TLBO and JA algorithms are more effective and stable for this structural model.

\subsection{Case 2}

Increasing the wall height from $6 \mathrm{~m}$ to $10 \mathrm{~m}$ caused the optimum $\mathrm{X}_{2}$ value, that is found zero in Case 1. The minimum cost design has been obtained with DE and TLBO algorithms. Besides, it is seen that JA and PSO obtained results very close to these results. Considering all the parameters obtained from the analysis results of the algorithms, it can be said that TLBO is better than the others.

\subsection{Case 3}

It is seen that all algorithms except GA have reached the optimum value. When all the statistical values are evaluated together, it is understood that the DE algorithm seems better, but there is no significant difference between the TLBO and JA algorithms. In terms of the number of iterations, the DE algorithm again reaches a slightly faster result. In terms of population numbers, it can be said that 15 to 30 population numbers are the most suitable range for optimum analysis.

\section{REFERENCES}

[1] J.H. Holland, Adaptation in natural and artificial systems, University of Michigan Press, 1975.

[2] D. E. Goldberg, Genetic algorithms in search, Optimization and machine learning, Boston MA: Addison Wesley, 1989.

[3] R. Storn, K. Price, Differential evolution-a simple and efficient heuristic for global optimization over continuous spaces. Journal of global optimization, 11(4), 341-359, 1997.

[4] X.S. Yang, Flower pollination algorithm for global optimization, International Conference on Unconventional Computing and Natural Computation, September HeidelbergBerlin, Springer, 240-249, 2012. 
[5] X. S. Yang, A New Metaheuristic Bat-Inspired Algorithm, in: Nature Inspired Cooperative Strategies for Optimization (NISCO 2010), Studies in Computational Intelligence, Springer Berlin. 65-74, 2010.

[6] S. Mirjalili, S.M. Mirjalili, A. Lewis, Grey wolf optimizer, Advances in Engineering Software, 69, 46-61, 2014.

[7] J. Kennedy, R.C. Eberhart, Particle swarm optimization. In: Proceedings of IEEE International Conference on Neural Networks No. IV, Perth Australia; November 27 - December 1. 1942-1948, 1995.

[8] M. Dorigo, V. Maniezzo, A. Colorni, The ant system: Optimization by a colony of cooperating agents. IEEE Transactions on Systems Man and Cybernet B 26, 29-41, 1996.

[9] R.V. Rao, V.J. Savsani, D.P. Vakharia, Teaching-learning-based optimization: A novel method for constrained mechanical design optimization problems, Computer-Aided Design, 43, 303-315, 2011.

[10] B. Ceranic, C. Fryer, R.W. Baines, An application of simulated annealing to the optimum design of reinforced concrete retaining structures, Computers \& Structures, 79(17) 15691581, 2001.

[11] V. Yepes, J. Alcala, C. Perea, F. Gonzalez-Vidosa, A parametric study of optimum earthretaining walls by simulated annealing, Engineering Structures, 30(3) 821-830, 2008.

[12] B. Ahmadi-Nedushan, H. Varaee, Optimal Design of Reinforced Concrete Retaining Walls using a Swarm Intelligence Technique, The first International Conference on Soft Computing Technology in Civil, Structural and Environmental Engineering, Stirlingshire, Scotland, 2009.

[13] A. Kaveh, A.S.M. Abadi, Harmony search based algorithms for the optimum cost design of reinforced concrete cantilever retaining walls, International Journal of Civil Engineering, 9(1) 1-8, 2011.

[14] C. V. Camp, A. Akin, Design of Retaining Walls Using Big Bang-Big Crunch Optimization, Journal of Structural Engineering, ASCE, 138(3) 438-448, 2012.

[15] R. Sheikholeslami, B. Gholipour Khalili, S.M. Zahrai, Optimum Cost Design of Reinforced Concrete Retaining Walls Using Hybrid Firefly Algorithm, International Journal of Engineering and Technology, 6(6) 465-470, 2014.

[16] P.E. Mergos, F. Mantoglou, Optimum design of reinforced concrete retaining wall with the flower pollination algorithm, Structural and Multidisciplinary Optimization, 2019, https://doi:10.1007/s00158-019-02380-x.

[17] A.H. Gandomi, A.R. Kashani, D.A. Roke, M. Mousavi, Optimization of retaining wall design using recent swarm intelligence techniques. Engineering Structures, 103, 72-84, 2015.

[18] R. Sheikholeslami, B.G. Khalili, A. Sadollah, J. Kim, Optimization of reinforced concrete retaining walls via hybrid firefly algorithm with upper bound strategy. KSCE Journal of Civil Engineering, 20(6), 2428-2438, 2016.

[19] Building Code Requirements for Structural Concrete and Commentary, (2014). ACI Committee, ACI 318. 